\title{
Peer-editing Practice in the Writing Classroom: Benefits and Drawbacks
}

\author{
Ann Rosnida Md. Deni \\ (Sunway University, Malaysia) \\ Zainor Izat Zainal \\ (Universiti Putra Malaysia) \\ doi:10.7575/aiac.alls.v.2n.1p.92
}

\begin{abstract}
Small scale studies have shown that peer-editing is beneficial to students as it increases their awareness of the complex process of writing, it improves their knowledge of and skills in writing and helps them become more autonomous in learning. Teachers too may benefit from peer-editing as this practice discloses invaluable information on students' writing weaknesses and strengths; and teachers' teaching effectiveness. This is a small scale study conducted on fifteen first-year degree students majoring in Tourism to view the usefulness of peer-editing practice in enhancing their writing skills. Retrospective notes were taken to record students' receptiveness and reaction towards peer editing practice; students' writing samples and peerediting questionnaires were analysed to view students' revisions and comments; and an openended questionnaire was distributed to identify students' perceptions of peer-editing practice in the writing classroom. Analysis of data gathered revealed that peer-editing practice benefitted both the teacher and most of her students as it exposed important information that could improve her teaching of writing and her students' writing practices. Data analysis also, however, discloses that peer-editing practice may have adverse effects on students' motivation and improvement in writing if they are not deployed properly.
\end{abstract}

\section{Peer feedback in the writing classroom}

According to Susser (1994, p. 35), one main element of the process approach to writing is to make students aware of writing as "a process of discovery in which ideas are generated and not just transcribed". To make writing a process of discovery, various types of activities are carried out in the writing classrooms, one of which is peer feedback. Peer feedback or also known as "peer response, peer editing, peer critiquing, and peer evaluation" (Keh, 1990, p. 295), can provide students with the opportunities to "discover and explore ideas... and 
negotiate with the audience about these ideas" (Mangelsdorf, 1989, p.143). A properly implemented peer feedback session can also help students develop a sense of audience (Leki, 1990; Tsui \& Ng, 2000, Mangelsdorf, 1992). Furthermore, peer feedback sessions can lead to the creation of students who can assess and improve their own writing (Lundstrom \& Baker, 2009). By responding to another person's writing, a student may become "a more critical reader and reviewer of their own writing" (Rollinson, 2005, p.24). Other than that, peer feedback practice may enhance cultural communication (Hansen \& Liu, 2005, p. 31), reduce writer's apprehension, develop learner autonomy and create confident writers (Coterall and Cohen, 2003). A study conducted by Yang, Badger \& Yu, (2006, p. 179), reveals that even in

cultures where teachers are the main authoritative figures, peer feedback practice "was associated with a greater degree of student autonomy".

\section{Problems with peer feedback}

Peer feedback practice has been proven through research to have positive effects on students' revision types and quality of texts (Berg, 1999; Min, 2006). Despite such positive findings, a number of research and experts have disclosed issues and problems that need to be addressed prior to implementation of peer feedback practice in class. One main problem with peer feedback is the low quality of feedback received. A study by Leki (1990) disclosed students' concerns over quality of feedback; the critical and sarcastic tones used and sincerity of peer reviewers. In addition, Flynn's (1982, as cited in Stanley, 1992, p. 219) study revealed peer reviewers offered "unhelpful and unfocused" feedback to their writing partners. Students may also produce "rubber stamp advice", imitating their own teachers' response to their writing (Leki, 1990, Min, 2005). Students' correction may also centre on grammar and vocabulary problems (Myles, 2004). Furthermore, students may tend to address surface errors and often fail to respond to problems in meaning (Stanley, 1992). Leki (1990) further posits that students who lack communication and pragmatic skills may not be able to convey quality peer responses. In situations where students are from different cultures, cultural misunderstanding may occur. Some cultures may refuse to accept student-centred activities (Mangelsdorf, 1992) and may find group work "very threatening and bewildering" particularly if the culture prohibits verbal criticism due to the need to save face (White, 1994, p. 115). In some learning environment where the teacher is viewed as "the only one real reader-- the person who gave the grade" (Sengupta, 1996, p. 25), peer feedback may not work at all. 
According to Berg (1999), responding to writing is not a skill that students are familiar with and requires the needs for opportunities to learn to respond to writing. In order for peer feedback sessions to be effective, many researchers thus advocate the need to pre-train or coach the students (Stanley, 1992; Berg, 1999, Rollinson, 2005; Min, 2006). Gere (1987 cited in Berger, 1990, p. 28) advocates the need to nurture students' trust, collaborative skills and critique writing in order to produce successful writing groups. Hansen and Liu (2005) suggest the need for teachers to first model the process of peer response and to provide ample time to familiarise students with peer response procedures. Due to the demand that peer feedback practice relies on the importance of coaching or pre-training, it is thus unsurprising to find many writing teachers excluding peer feedback sessions from their classes as they can be both "lengthy" and time consuming (Rollinson, 2005, p.23).

\section{Rationale and significance of study}

The study on peer feedback carried out by the teacher took place in a learning environment where time was an issue. Extra time to conduct training on peer feedback required the teacher to carry out the session outside class time which would not be welcomed by the students who had a very packed schedule. The teacher, however, was a strong proponent of peer feedback and believed that despite the unfavourable environment, peer feedback sessions could still be carried out successfully. To reduce probability of students giving tactless, inappropriate responses to other's writing, peer-editing checklists were utilised in the writing lessons. According to Lamberg (1990, p. 68), the use of writing checklists can guide students in peerresponse activities. Furthermore, the use of checklists can increase students' "critical sensibilities", check students' understanding and raise "text-based questions" (Dheram, 1995). Paulson (1992), another supporter of the use of checklists in the writing classroom, states that checklists that list down items such as "comprehensibility" and "cohesiveness" may channel students attention to global items, not only focusing on grammar. Myles (2004, p. 259) believes that checklists would "open doors for more interaction between the student and teacher and between students" which can be useful as "focal points for discussion."

To guide students in the process of editing others' work and in interpreting others' comments on one's writing, the teacher also included writing conferences at the end of each peerfeedback sessions. A study conducted by Curtis (1997, as cited in Jacobs, Curtis, Braine, \& Huang, 1998, p. 313) reveals that students valued both teacher and peer feedback. A questionnaire survey of 121 L2 undergraduate students revealed that $93 \%$ of the students 
surveyed wanted peer feedback when it was accompanied by teacher feedback (Jacobs, Curtis, Braine, \& Huang, 1998). A study by Tsui \&Ng (2000, p. 167-168) reveals that students favoured both teacher and peer comments as teacher comments tend to "induce more revisions" and peer comments promotes "a sense of 'real' audience, raising students' awareness of strengths and weaknesses of their own writings..." Incorporating writing conferences would provide opportunities for oral feedback that has potential for negotiation of meaning (Hyland \& Hyland, 2006) and it would help students in rectifying writing weaknesses identified by peer reviewer (Mangelsdorf, 1992). During writing conferences, the teacher plays the role of a participant in the writing process where students are able to "ask for clarification... help writers sort through problems and assist students in decision-making" (Keh, 1990, p. 298).

The objective of this study is to view the usefulness of peer feedback practice in enhancing students' writing skills. It is significant as it provided useful insights on pedagogical aspects involving peer feedback practice in a time-constraint environment. It would also supply other teachers with information on the benefits and drawbacks of peer feedback practice experienced by the teacher in her teaching environment.

\section{The participants/ setting}

The study took place in a private university college involving 15 first and second semester degree students majoring in Tourism and Hospitality Service Industry. All degree students are required to take up an English for Specific Purpose course and the participants were required to undertake UCS1002- English for Tourism Service Industry. UCS 1002 focuses on three main areas: the first area focuses on developing relevant reading skills for effective reading of academic text (10 hours); the second area focuses on developing academic writing skills particularly on using appropriate style, tone and format in writing academic essays and project papers (24 hours); and the third area focuses on developing specific writing skills needed for tourism service industry (English for Workplace) (20 hours). All students who have taken up the course are required to pass it as it is one of the University College's Compulsory Subjects.

During the study, students were required to produce two academic essays-the first essay was written in groups where students were required to select a topic to write collaboratively based on several specific tourism/ hospitality topics given. The first peer feedback session was also 
conducted in groups and in this instance students were not given the opportunity to select the groups that would respond to their writing. The second part of the study required the students to write a cause-and- effect essay; on the effects of cultural tourism on society. The second essay was produced individually and during the second peer feedback session, students were allowed to choose their own peer editors. Most students chose their friends or someone that they were always seated with in class to be their peer editors.

The class consisted of students of different nationalities; 4 Malaysians, 1 from Thailand, 1 from Myanmar, 2 from Iran, 1 from Botswana, 1 from Maldives, 5 from Indonesia (one of the Indonesian students is a resident of Dubai), Participants were a combination of students from the elementary level ( 3 students), to the intermediate ( 9 students) and upper-intermediate level (3 students) in English. Five out of fifteen students have done peer editing before and the rest had no experience in editing other's works.

\section{Nature of study and data collection}

The study conducted has qualitative features as it took place in its natural setting and it was "emergent rather than tightly prefigured" (Cresswell, 2003, p. 181). Activities carried out during the study were determined by students' writing test results, students' reactions towards peer editing practice and time permitted to carry out these activities. Three methods were utilised to collect data to identify the usefulness of peer-editing practice in enhancing students' writing skills and to identify the benefits and drawbacks of peer feedback practice. Notes were written down immediately after class to record peer reviewers' reaction when they were editing others' writing and to record reactions of receivers of feedback. Students' writing samples and peer-editing questionnaires were analysed to view students' revisions and comments; and an open-ended questionnaire was distributed to identify students' perceptions of peer-editing practice in the writing classroom.

\section{The checklist}

The peer-editing checklist comprised of four main sections 1) Content and Organisation-

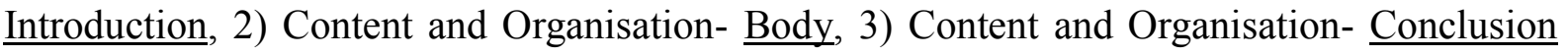
and 4) Others. As the teacher needed to cover the syllabus at the same time, the checklists distributed to the students covered contents that were taught in class. It contained statements and questions that examined the ability of the students to: 


\section{Introduction}

1) identify the type of introduction that was used

2) evaluate whether the introduction was interesting

3) evaluate whether the thesis statement was clear

4) identify whether the thesis statement contained a preview of main ideas

Body

1) identify whether the topic sentences in all the body paragraphs were clear ( if not clear, students were required to underline the parts that were unclear)

2) identify the type of supporting details used in the body paragraphs

3) identify whether there were any sentences that were off the topic (students were required to underline all unnecessary sentences)

4) evaluate whether the body was coherent-flow smoothly from beginning to end (if yes, they were required to tick the type of cohesive devices that were used - repeating key nouns, using consistent pronouns or using transition links to link ideas within paragraphs)

5) indicate the expressions that were used to link ideas between paragraphs (if there were any)

\section{Conclusion}

1) indicate the expression used to introduce the conclusion

2) identify whether the writer summarized the main points or paraphrased the thesis statements in the conclusion

3) evaluate whether the conclusion has an effective ending

4) identify whether the writer introduced a new idea

\section{Others}

1) indicate the best features of the essay

2) indicate the areas that need further improvement

\section{Procedure}

The study was divided into two separate stages. The first stage involved a writing test to determine students' level in writing. Students were then introduced to the academic writing style and tone, the process of writing (prewriting, drafting, revising) and essay writing (thesis 
statement, components of an essay, topic sentences, coherence, cohesion) and they were then required to select a topic based on the lists of tourism and hospitality topics given. Students' marking samples indicated that most of the students in the class have serious problems in writing involving both local and global concerns. Due to this, the teacher decided that the first writing task and the first peer editing session were done in groups. This, she believed, could assist students in their writing and in editing others' work as both tasks would be done as a collaborative effort. Students who selected topics were required to be seated together and produce an essay based on the topic selected. These essays were then collected and given to two other groups to edit. A peer-editing checklist was given to each group to assist them in the process of peer editing. When editing others' work, students were also allowed to 'mark' the essay. The pieces of writing and the completed peer-editing checklists were stapled together and handed in to the teacher. Edited pieces of writing and content of checklist were then checked by teachers. Before giving them back to the rightful owner, the teacher would carry out a writing conference with the peer response groups to clarify comments made by them that she found unclear. She would then carry out a writing conference with the writers of the essay to discuss the content of the essay and the corrections made by peer response group. During the writing conference, the teacher would 'highlight' mistakes made by the writers that were not identified by their peer reviewers. In Stage 1, the peer response group and the receivers of feedback did not 'meet up' to discuss contents of writing and checklists.

The second stage was carried out after lessons on cause-and-effect essay. Findings from analysis of data collected during Stage 1, affect Stage 2 of the study in the following ways: Students with low-proficiency level would not be involved in the second stage and their future writing would be evaluated by the teacher; students were allowed to choose a peereditor that they were comfortable with; and students were not allowed to write comments on other's writing. Comments could only be written on the checklists and students were only allowed to underline the thesis statement and topic sentences found in their partner's paper.

In the second stage, students were asked to write an essay on the effects of cultural tourism on society. After the essay was written, student will exchange his/ her paper with one another and using the checklist given, students edit each other's work. As in stage 1, students were also allowed to write comments in the essay. The essay together and the completed checklist were then handed in to the teacher. The teacher would first check each edited writing and checklist. She would then carry out a writing conference with the peer editor to clarify 
comments made on the essay and the checklist. The teacher would then return the edited piece of writing to the writer and discuss the content of the essay and the checklist together with the peer editor. During the writing conference, the teacher would again 'highlight' mistakes made by the writers that were not identified by their peer reviewers.

\section{Findings derived from retrospective notes}

Before findings from retrospective notes are discussed, it is vital to explain the grouping of students in Stage 1. In Stage 1, students were divided into 4 groups. Group A consisted of five students, a combination of two upper-intermediate level students and three lower intermediate students; Group B consisted of five students of intermediate level; Group C comprised of three students of intermediate level and the last group, Group D, comprised of one upper-intermediate level and one intermediate level student. Groupings were determined by the topic that students selected. Students who selected the same topic would be placed in the same group.

\section{Reaction of peer editors}

During Stage 1, it was observed that only two students (upper-intermediate) in Group A were editing other groups' writing. The other three students did not take part in the editing process and two totally lost interest in the task. Students from Group B were found to be engrossed in the editing process. Students in Group B appeared like they 'enjoyed' analysing others' writing and they were found to be carrying out lengthy discussion on both local and global matters. While discussing the content, the teacher overheard one of the students commenting, "This is how it feels to be the reader." During the discussion, the teacher identified some error identification done by Group B were spot on but some were totally wrong. Teacher's observation of Group B disclosed that students in the group were critical of others' writing. Group C consisted of average writers and they too were found to be thoroughly involved in the peer editing process. Good D consisted of two 'individual' writers. While editing others' work, there was hardly any discussion carried out between the two students. Once one student finished editing a piece of writing, she would then pass it to the other student in the group who would then re-edit the paper.

In Stage 2, all peer editors were found to be engrossed in the process of editing their friend's writing. At this stage, four students (one intermediate level and three elementary level) were not involved in the second stage of the study; two had dropped out of the course and the other 
two (elementary level) had to be given other writing tasks as peer-editing was too difficult for them.

\section{Reaction of receivers of feedback}

During Stage 1, all groups, except for Group C, were receptive of the comments made by other students. Group A, B, D appeared 'happy' when they discussed comments made by other groups. Only Group C appeared 'upset' upon receiving their edited writing (together with the checklists). They started blaming one another for some of the spelling mistakes identified by other groups. They mentioned several times to the teacher during the writing conference that they have tried their best in writing the essay. One of the group members mentioned this again before she left the class. (Group $\mathrm{C}$ took the longest time to produce the essay).

During Stage 2, there was no significant observation that could be reported as students were seen to be receptive of each other's comments on each other's writing.

\section{Findings derived from analysis of peer editing checklists.}

Analysis of peer editing checklists gathered from Stage 1 and 2 revealed that students were able to identify weaknesses in others' writing. For example, one of the peer response group who edited Group C's writing (Stage 1) succeeded in identifying problems with the writing which were unclear thesis, and lack of coherence in writing. In addition, both peer response groups who edited the piece of writing generated by Group D, succeeded in pinpointing problems which included both local (grammar, sentence structure, vocabulary problems) and global concerns (lack of unity). Both peer response groups who were editing Group A's writing also managed to identify the problem in writing which was lack of coherence. In the second stage of the study, one peer editor, was successful in identifying all the problems that her friend had in her writing which ranged from unclear thesis and topic sentences, inadequate support, lack of unity and coherence to ineffective ending. Analysis of peer editing checklists has also revealed that some students were able to detect strengths in others' writing. One peer editor for example was able to identify the strength in her partner's writing which was the quality of points used to support the topic.

Despite these positive findings, analysis of checklists revealed that in some instances, some students, regardless of whether they were working in groups or individually, were not able to 
identify problems and strengths of others' writing. One peer response group who edited Group C's writing, for example, indicated that the thesis statement was unclear when it was clearly stated and even contained preview of main ideas. Another example is of a peer editor who indicated that her partner's thesis was clear when it was in fact presented in two separate sentences and was very lengthy (6 lines). Another peer editor commented that her partner's conclusion was the main aspect of the essay that needed to be improved when in fact, nothing was wrong with it as it contained the recapitulation of the thesis statement, it was appropriately developed (from specific to general) and it provided closure to her partner's writing. Analysis of the checklist also revealed students' confusion. In Stage 1, for example, one of the peer response groups who evaluated Group A's essay detected coherence problem (the most prominent problem) in its writing but indicated that the best feature of the essay was "the flow of the essay".

Further scrutiny of peer editing checklists revealed that even though some students were able to be specific with the comments that they gave on the strengths and weaknesses of others' writing, many gave vague comments. Some written comments on the best features of the essays edited were "vocabulary"; "the main body"; "the explanation and examples"; and "handwriting" and some of the written comments on areas that need to be improved include "conclusion"; "grammar"; "how to end paragraph"; "cohesion"; "effective conclusion" ; and "conclusions".

Through writing conferences, these problems were highlighted and teacher indicated other problems that exist in students' writing. Without the writing conferences, the teacher believed that the peer editing practice would only result in serious confusion on what constitutes good or bad writing.

\section{Findings derived from students' writing}

Analysis of students' writing indicated that correction made on some essays were mostly on lower order concerns (spelling, grammar, vocabulary, sentence structure etc.). In most instances, peer response groups were able to identify errors and made accurate correction on another group's writing. One peer response group who edited Group C's essay, for instance, managed to locate and correct most surface errors, for example: (these (this) process; [We] (not academic writing) can witness different nations (upgrading) the transport systems...; In addition, nations [really up] (vocabulary) their tourism and hospitality 
business...". Other examples were from Group B's edited writing. One of the peer response groups who edited its essay made corrections on the following surface errors: "Negotiating skill is-also plays an important role in order to (achieve) the establishment sales target..."; "Pespite (Other than) job-related skills, employees also need to have communication skills in this (the) tourism industry.

Analysis of edited Group C's essay, however, also revealed that the peer response group had made 'corrections' on items that were accurate in the first place. For example, the group substituted 'such as' with 'for example'.

Only two peer response groups attempted to identify a global problem with another group's writing when it indicated that a paragraph in the essay was not cohesive and this was spot on. One group wrote comments like "Incohesive" and "it's hanging, should have better ending for this paragraph" and the other group wrote "No clear explation (supposed to be explanation) between the second point and the conclusion"

One group, Group B, in particular, was writing down rubber stamps comments that made them sound like the teacher. Examples of these comments were "be more specific"; "topic sentence- not clear"; "??you did not mention"; "advantage is a better word"; "etc. should not be used."

Problems on meaning and other global concerns and major language problems (for example sentence fragments), were mostly detected by the teacher and these were highlighted during the writing conference. Without the writing conferences, the teacher believed that students would not know which comments to take seriously and which should be ignored.

\section{Findings derived from open-ended questionnaire}

Twelve students answered the questionnaire and analysis of findings from the open-ended questionnaire revealed that eleven students (91.6\%) were generally positive of the peer feedback practice. Students indicated that they found the peer editing practice 'interesting', 'challenging' and 'useful' and they also stated that the peer editing practice:

- helps (me) to understand what is expected 
- provides students with the chance to view and understand different ways of answering the same (essay) question

- helps find mistakes that I didn't see

- is important because we will know about others' work

- can help students 'learn from each others' writing styles'

- help 'new ideas to come into view'

- help discovers 'how the teachers check the work of students and it is not easy'

Only one student voiced her concern over the benefits of peer editing practice. She indicated that peer editing did not really work for her due to the following stated reasons:

- I don't really go through the essay. I don't know the advantage or benefit of it.

- Me and my friend still in the learning process, so he/ she might not give correct or effective editing

- I don't really concern about my friend's comments. It is more accurate and effective if the comments come from the lecture him/herself to guide me to a better quality of work.

Analysis of questionnaire also revealed that $58 \%$ of the students generally felt either positive or neutral towards their peer editors. The rest were quite sceptical as they were worried of the quality and sincerity of the comments given. Students indicated the following to voice their concerns:

- I don't really believe or trust my friend's comments.

- If the peer editor is good and knows what he/ she is doing, I will feel that he/ she is helping me. If it is the other way round, I may think twice about her ability (in editing my work).

- Because the editors are students, they may not know how to analyse and critic a person's report. If there is a language barrier, it will be more difficult.

- I appreciate those who honestly want to help correct, learn and give sincere comments or suggestions 
When asked whether students took the peer editors' comments seriously, $41.6 \%$ of the students indicated that they were either reluctant to accept or sceptical of the peer editors' comments. These students stated the following to reveal their reluctance or scepticism over the peer editors' comments:

- Not really. Because sometimes the hand writing is difficult to read. It's boring.

- Not really. Sometimes the editors were not serious when they edit/ comment others' work

- Not exactly seriously

- Yes, if he/ she is knowledgeable than me

- I don't really take the comments seriously. I think that the lecture will give me better comments or maybe correct my mistakes... more effectively

When asked what students thought of the peer editing checklist, 58\% responded positively to its use during peer editing sessions. Students indicated that "it helped to provide guidelines"; "it is quite straightforward... we can learn about or weakness and which areas we need to improve on". The rest, (42\% of the students) were not however very 'happy' with the content of the peer editing checklist describing it as either "too descriptive"; "a bit confusing"; or "unclear".

\section{Conclusion and pedagogical implications}

The study was not able to neither prove nor disprove the usefulness of peer editing practice in improving students' writing skills. (At the end of the study, the objective in fact sounded ambitious). One of the main reasons was due to too much teacher intervention during writing conferences. Students' improvement in writing, if any, may be owed to teacher's feedback and not peers. Despite this, the study has proven the usefulness of peer editing practice in other aspects, for example, in making the classroom environment more interesting and challenging; in providing venues for students to share, explore and identify different ideas and approach to responding to a writing task; and to learn from one another particularly on different styles of writing.

Analysis of data revealed, through the three data collection methods, shows that drawbacks of peer editing practice outweigh its benefits. One of the main drawbacks is the low quality of 
peer editors' feedback. Students' giving out confusing, inappropriate or 'rubber stamp' comments could make peer feedback a detrimental process to students' motivation level and most importantly to their writing. Another drawback of peer feedback practice is the low receptivity of the comments received from peers by nearly $40 \%$ of the students who took part in the study. This, she believes, was due to improper grouping, limited guidelines given and inadequate checklists.

If future peer editing projects are to be implemented in her writing classrooms particularly if they comprised of students with lower proficiency level, the teacher should take the following considerations to improve the usefulness of the practice.

One area that needs to be improved is on the quality of guidelines and the way they are provided. In this study, students were verbally guided throughout the process. In the beginning they were verbally introduced to the practice where teachers informed them of the benefits of such practice but she did not provide guidelines in black and white. She believed that the checklists and the writing conferences would be adequate to guide the students through the process. However, this was proven wrong. If future peer editing projects are to take place in her writing classrooms, since time will still be limited to pre-train the students, she should provide students with handouts on the following: the benefits of peer feedback, what entails good peer feedback and bad peer feedback and samples of essays that were properly edited by students. She will then carry out (at least one time), a class editing session where an essay will be projected on a screen and the whole class will be editing the essay together. Teacher will model to the students, the appropriate comments to write on the essay and the checklist and the symbols to use when editing others' work. By doing this, she believes the number of useless and inappropriate comments given will be limited, which would improve the level of receptivity of peer comments and thus improve the usefulness of peer feedback practice.

Another area that needs to be improved is on the way grouping is handled. Group editing seems to be ineffective particularly when there is a combination of two levels of proficiency in a group. To avoid this from happening, if group editing is to be reintroduced in her writing classroom, she should either allow students to choose their own editors or put the students with the same level of proficiency in one group. This will also apply to situations when students are required to peer edit other's work on a one-to-one basis. This, she believes, can 
help her in managing peer editing sessions better and most importantly, reduce inhibitions and improve receptivity of comments.

As for the content of the checklists, she believes that this should be upgraded to provide better guidelines. She noticed that the peer editing checklist utilised was not comprehensive enough as certain problems like improper in-text citations, were not addressed. Wordings in the checklists need to also be carefully revised as words like 'cohesive devices', 'coherence', 'topic sentences', 'unity', 'thesis statement' which despite being introduced in lessons prior to peer editing sessions, could still be too 'big' to some students. These changes thus have to be made to the checklist to enable students to give better and proper peer feedback.

Future practice would include writing conferences as she believes that without this, the peer editing practice, particularly if it is carried in a teaching environment where time is an issue and students are of lower proficiency level, will just be a waste of time and may even have damaging effects on students' motivation level and students' writing skills.

According to Mangelsdorf (1992, p. 282), "As with other pedagogical techniques, peer reviews require the teacher to be flexible". The teacher believes that this is indeed true. Future peer editing sessions should be tailor made to suit students' needs and wants and their receptivity level of the task. There is no point of carrying out writing activities that would have more downsides than benefits to the students. At the end of the day, it is all about choosing activities that work for them. 


\section{References}

Berg, E. C. (1999). The effects of trained peer response on ESL students' revision types and quality. Journal of Second Language Writing. 8(3), 215-241.

Berger, V. (1990). The effects of peer and self-feedback. CATESOL Journal, 21- 33.

Cotterall, S. \& Cohen, R. (2003). Scaffolding for second language writers: producing an academic essay. ELT Journal. 57(2), 158- 166.

Creswell, J. W. (2003). Research design. Qualitative, quantitative, and mixed methods approaches. ( $2^{\mathrm{nd}}$ Ed.). London: SAGE publications.

Dheram, P. K. (1995). Feedback as a two-bullock cart: a case study of teaching writing. ELT Journal. 49(2), $160-168$.

Hansen, J. G. \& Liu, J. (2005). Guiding principles for effective peer response. ELT Journal. 59(1), p. 31- 38.

Hyland, K. \& Hyland, F. (2006). Feedback on second language students' writing. Language Teaching. 39, 83101.

Jacobs, G. M., Curtis, A., Braine, G. \& Huang, S. (1998). Feedback on student writing: Taking the middle path. Journal of Second Language Writing. 7(3), 307-317.

Keh, C. (1990). Feedback in the writing process-a model and methods for implementation. ELT Journal. 44(4), 294-304.

Lamberg, W.(1990). Self-provided and peer-provided feedback. College Composition and Communication. (311), 63-69.

Leki, I. (1990). Potential problems with peer responding in ESL writing classes. CATESOL Journal, 5-19.

Lundstrom, K., \& Baker, W., (2009). To give is better than to receive: The benefits of peer review to the reviewer's own writing. Journal of Second Language Writing. 18 (1), 30-43.

Mangelsdorf, K. (1989). Parallels between speaking and writing in second language acquisition. In D.M. Johnson \& D.H. Roen (Eds.), Richness in writing: Empowering ESL students. pp. 134- 145. New York: Longman.

Mangelsdorf, K. (1992). Peer-reviews in the ESL composition classroom: what do students think? ELT Journal. 46(3), 274- 284.

Min, H. (2005). Training students to become successful peer reviewers. System. 33, 293- 308.

Min, H. (2006). The effects of trained peer review on EFL students' revision types and writing quality. Journal of Second Language Writing. 15, 118-141.

Myles, J. (2004). Feedback processes in second language writing: Conflict in student and teacher Preferences. In K. Kaur \& M.E Vethamani. (Eds). Second Language Writing (pp. 254-274). Kuala Lumpur: Sasbadi.

Paulson, D. (1992). Assessment of FL learners' Writing Ability: Formulation of Tasks and Evaluation. ERIC Document Reproduction Service No. ED 342249.

Rollinson, P. (2005). Using peer feedback in the ESL writing classroom. ELT journal. 59(1), 23-30.

Tsui, A.B.M \& Ng, M. (2000). Do second L2 writers benefit from peer comments. Journal of Second Language Writing. 9 (2), 147-170.

Sengupta, S. (1996). Peer-evaluation: 'I am not the teacher'. ELT Journal. 52(1), 19- 28.

Stanley, J. (1992). Coaching student writers to be effective peer evaluators. Journal of Second Language Writing. 1(3), 217-233.

Susser, B. (1994). Process Approaches in ESL/EFL Writing Instruction. Journal of Second Language Writing. 3 (1), 31- 47.

White, E. (1994). Teaching and Assessing Writing. San Francisco:Jossey Bass Publishers.

Yang, M., Badger, R., \& Yu, Z. (2006). A comparative study of peer and teacher feedback in a Chinese EFL writing class. Journal of Second Language Writing, 15, 179-200. 